\title{
Influence of oxidative atmosphere of the electron beam irradiation on cyclization of PAN-based fibers
}

\author{
Hye Kyoung Shin ${ }^{1}$, Mira Park ${ }^{2}$, Hak-Yong Kim² and Soo-Jin Park ${ }^{1, \text {, }}$ \\ ${ }^{1}$ Department of Chemistry, Inha University, Incheon 402-751, Korea \\ ${ }^{2}$ Department of Organic Materials and Fiber Engineering, Chonbuk National University, Jeonju 561-756, Korea
}

\section{Article Info}

Received 29 December 2014 Accepted 15 March 2015

*Corresponding Author

E-mail: sjpark@inha.ac.kr Tel: $+82-32-876-7234$

\section{Open Access}

DOI: http://dx.doi.org/

10.5714/CL.2015.16.3.219

This is an Open Access article distributed under the terms of the Creative Commons Attribution Non-Commercial License (http://creativecommons.org/licenses/ by-nc/3.0/) which permits unrestricted non-commercial use, distribution, and reproduction in any medium, provided the original work is properly cited.

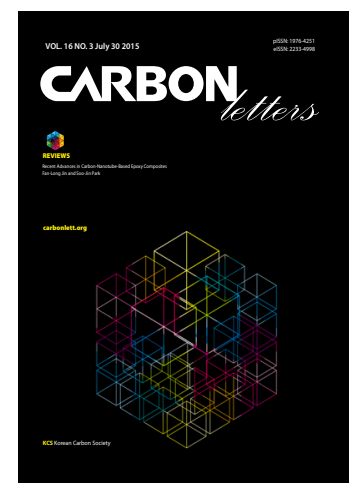

http://carbonlett.org

pISSN: 1976-4251

elSSN: 2233-4998

Copyright $\odot$ Korean Carbon Society

\begin{abstract}
In order to study the impact of atmosphere during electron beam irradiation (EBI) of polyacrylonitrile (PAN) precursor fibers, the latter were stabilized by EBI in both air and oxygen atmospheres. Gel-fraction determination indicated that EBI-stabilization under an oxygen atmosphere leads to an enhanced cyclization in the PAN fibers. In the Fourier-transform infrared spectroscopy analysis, the PAN fibers stabilized by EBI under an oxygen atmosphere exhibited a greater decrease in the peak intensity at $2244 \mathrm{~cm}^{-1}(\mathrm{C} \equiv \mathrm{N}$ vibration $)$ and a greater increase in the peak intensity at $1628 \mathrm{~cm}^{-1}(\mathrm{C}=\mathrm{N}$ absorption) than the corresponding PAN fibers stabilized under an air atmosphere. From the X-ray diffraction analysis it was found that oxygen uptake in PAN fibers leads to an increase in the amorphous region, produced by cyclization.
\end{abstract}

Key words: electron beam irradiation, stabilization, carbon fibers, polyacrylonitrile

\section{Introduction}

In order to produce high-performance carbon fibers from polyacrylonitrile (PAN) precursor fibers, the process of stabilization plays an important role [1-10]. In this process, linear polymers of $\mathrm{C} \equiv \mathrm{N}$ groups in the PAN fibers are converted into ladder polymers by various methods, including cyclization, cross-linking, dehydrogenation, and oxidation [11,12]. These ladder structures enhance the thermal stability of the PAN fibers, thus preventing them from melting during carbonization at temperatures over $1000^{\circ} \mathrm{C}$. Hence, the parameters of the stabilization process are expected to have a strong impact on the strength of the resulting carbon fibers.

Electron beam irradiation (EBI) has been widely applied in the modification of various materials in the absence of solvents or additives, at room temperature, due to its ability to induce a variety of changes in properties, through chain scissioning, polymerization, and crosslinking. In the past, many researchers focused on thermal stabilization of PAN fibers to produce high-performance carbon fibers. However, the use of EBI as a stabilization process [13-18] is currently becoming widespread for various reasons, including lower energy consumption and a reduced stabilization time. In particular, the control of various atmosphere conditions during the stabilization process can accelerate the cyclization reaction.

In this study, PAN fibers were irradiated under different conditions of air and oxygen atmosphere at room temperature. The PAN fibers stabilized by EBI under both atmosphere conditions were characterized by gel fraction, Fourier-transform infrared spectroscopy (FTIR), and X-ray diffraction (XRD) analysis. 


\section{Experimental}

\subsection{Materials and EBI stabilization}

Raw PAN fibers were obtained from Anshan East Asia Co., Ltd., China. The obtained PAN fibers were irradiated with 2 MGy using an EB accelerator at an accelerating voltage of 1.14 $\mathrm{MeV}$ with a beam current of $4 \mathrm{~mA}$ under the two types of atmosphere.

\subsection{Analysis}

Dimethyl-formamide (DMF) was used as a solvent to measure the gel fraction of the EBI-stabilized PAN fibers. The samples were extracted in DMF at boiling temperature for $24 \mathrm{~h}$. The residual gel contents were dried in vacuum at $80^{\circ} \mathrm{C}$ for $48 \mathrm{~h}$. The gel fraction determination was defined as the weight percent of insoluble parts according to the following equation:

$$
\text { Gel content }(\%) \frac{\text { Residual weight }}{\text { original weight }} \times 100
$$

FT-IR analyses were performed using a Nicolet 7700 spectrometer with the $\mathrm{KBr}$ method to determine changes in the functional groups within the PAN fibers. The wavelengths used were in the range of $4000-650 \mathrm{~cm}^{-1}$ and the spectra obtained contained the results of 30 scans at a spectrophotometer resolution of 8 $\mathrm{cm}^{-1}$. An X-ray diffractometer (RIGADU D/MAX-2500) with $\mathrm{CuK} \alpha$ radiation, generated at $40 \mathrm{kV}$ and $30 \mathrm{~mA}$, was used over the $2 \theta$ range of 5-50

\section{Results and Discussion}

Fig. 1 shows the gel fraction values which account for the degree of cyclization of the EBI-stabilized PAN fibers, according to the different EBI doses applied under air or oxygen conditions. From Fig. 1 it is apparent that the gel content of the EBI-stabilized PAN fibers gradually increased with increasing EBI dose under both air and oxygen conditions. It is also evident that the specific atmosphere condition used clearly affected the degree of cyclization in the PAN fibers. In fact, the degree of cyclization in the PAN fibers stabilized by EBI under an oxygen atmosphere were higher than those in the corresponding PAN fibers stabilized under an air atmosphere. In the former case, the maximum gel content was approximately $95.6 \%$ at $2000 \mathrm{kGy}$ of EBI dose. This outcome can be due to an acceleration of the conversion of $\mathrm{C} \equiv \mathrm{N}$ groups into $\mathrm{C}=\mathrm{N}$ groups brought about through oxygen uptake.

In order to understand the conversion of $\mathrm{C} \equiv \mathrm{N}$ groups into $\mathrm{C}=\mathrm{N}$ groups in EBI-stabilized PAN fibers, we conducted FT-IR analyses, as depicted in Fig. 2. In the case of the PAN precursor fibers, the peaks for the $\mathrm{C}-\mathrm{H}$ and $\mathrm{C} \equiv \mathrm{N}$ stretching vibrations were observed at $1451 \mathrm{~cm}^{-1}$ and $2244 \mathrm{~cm}^{-1}$, respectively. In the presence of an oxygen atmosphere, the intensities of these peaks decreased compared to their intensities in an air atmosphere. However, the intensity of a new peak at $1628 \mathrm{~cm}^{-1}$, which was attributed to the $\mathrm{C}=\mathrm{N}$ absorption mode, increased gradually in the following order: PAN precursor fibers $<$ PAN fibers stabi-

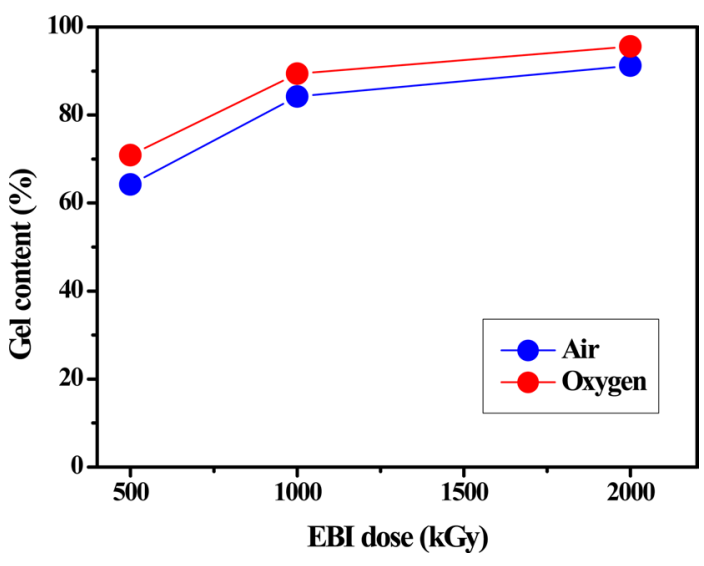

Fig. 1. Gel fraction for the polyacrylonitrile fibers stabilized by electron beam irradiation $(\mathrm{EBI})$ under air or oxygen atmosphere conditions.

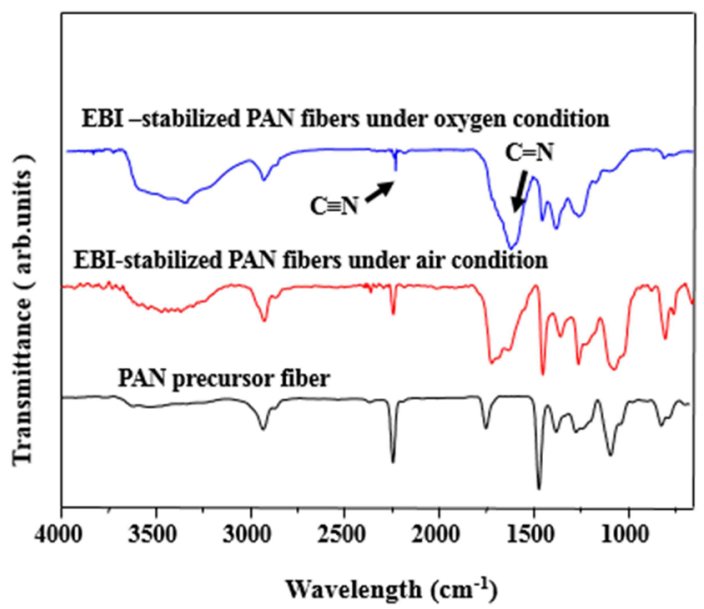

Fig. 2. Fourier-transform infrared spectra of the polyacrylonitrile (PAN) precursor fibers and PAN fibers stabilized by electron beam irradiation (EBI) under air or oxygen atmosphere conditions.

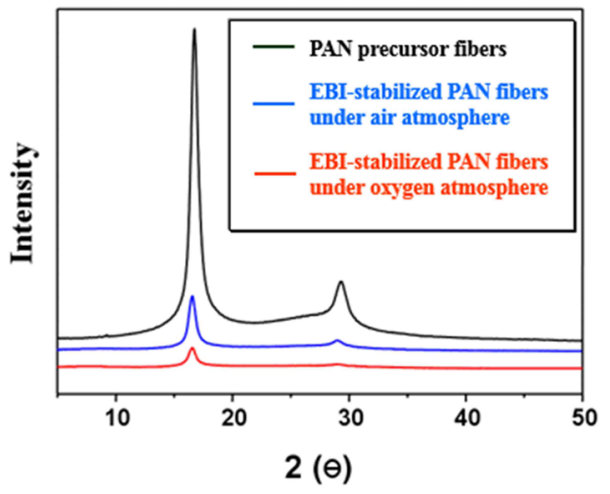

Fig. 3. X-ray diffraction patterns of polyacrylonitrile (PAN) fibers and electron beam irradiation (EBI)-stabilized PAN fibers under air or oxygen atmosphere.

lized by EBI under air atmosphere < PAN fibers stabilized by EBI under oxygen atmosphere. These results provide evidence that an oxygen atmosphere can greatly enhance the cyclization degree during EBI-stabilization. 
Table 1. XRD data of PAN fibers and EBI-stabilized PAN fibers under air or oxygen atmosphere

\begin{tabular}{ccc} 
Sample & Peak intensity (CPS) & FWHM $\left(^{\circ}\right)$ \\
\hline PAN precursor fibers & 32548 & 0.78 \\
\hline $\begin{array}{c}\text { EBI-stabilized PAN fibers } \\
\text { under air atmosphere }\end{array}$ & 5989 & 0.94 \\
\hline $\begin{array}{c}\text { EBI-stabilized PAN fibers } \\
\text { under oxygen atmosphere }\end{array}$ & 2875 & 1.02 \\
\hline
\end{tabular}

XRD: X-ray diffraction, PAN: polyacrylonitrile, EBI: electron beam irradiation, FWHM: Full width at half maximum.

Fig. 3 exhibits the major changes in the EBI-stabilized PAN fibers according to the air or oxygen conditions used, as observed through the XRD spectra. These results are further summarized in Table 1. In Fig. 3, a major peak at a $2 \theta$ value of $16^{\circ}-17^{\circ}$ was associated with the (100) plane of a hexagonal structure, thus indicating the crystalline structure of the PAN fibers.

As shown in Fig. 3 and Table 1, the intensity of the peak for EBI-stabilized PAN fibers largely decreased compared to the one for the PAN precursor fibers. Furthermore, the intensity of the peak for the PAN fibers stabilized by EBI under an oxygen atmosphere decreased more than that of the PAN fibers stabilized by EBI under an air atmosphere, while the full width at half maximum value increased. These results are due to an increase in amorphization by cyclization in the EBI-stabilized PAN fibers.

In conclusion, the PAN precursor fibers investigated in this study were stabilized by EBI under air or oxygen atmospheres. The gel contents of the EBI-stabilized PAN fibers at $2000 \mathrm{kGy}$ under an oxygen atmosphere reached values of about $95 \%$. From the FT-IR analysis, it was found that the increase in the intensity of the $\mathrm{C} \equiv \mathrm{N}$ vibration peak at $2244 \mathrm{~cm}^{-1}$ and the decrease in the intensity of the $\mathrm{C}=\mathrm{N}$ absorption peak at $1628 \mathrm{~cm}^{-1}$, which were more apparent for the PAN fibers stabilized by EBI under an oxygen atmosphere than for those stabilized under an air atmosphere, are highly correlated with the transformation of linear groups into cyclized groups. In the XRD analysis, the PAN fibers stabilized by EBI in the presence of oxygen display decreased peak intensities. These results may be an indication that the oxygen uptake in the PAN fibers causes a higher destruction of the crystalline regions due to an increase in the amorphous regions through cyclization.

\section{Acknowledgements}

This work was supported by Carbon Valley Project of the Ministry of Trade, Industry and Energy, Korea.

\section{References}

[1] Park SJ. Carbon Fibers, Springer Series in Materials Science, Vol. 210, Springer, New York, NY (2015)

[2] Minus M, Kumar S. The processing, properties, and structure of carbon fibers. JOM, 57, 52 (2005). http://dx.doi.org/10.1007/ s11837-005-0217-8

[3] Chand S. Carbon fibers for composites. J Mater Sci, 35, 1303 (2000). http://dx.doi.org/10.1023/A:1004780301489.

[4] Beltz LA, Gustafson RR. Cyclization kinetics of poly(acrylonitrile). Carbon, 34, 561 (1996). http://dx.doi.org/10.1016/00086223(96)00005-X

[5] Fitzer E. PAN-based carbon fibers: present state and trend of the technology from the viewpoint of possibilities and limits to influence and to control the fiber properties by the process parameters. Carbon, 27, 621 (1989). http://dx.doi.org/10.1016/00086223(89)90197-8.

[6] Park SJ, Seo MK, Rhee KY. Effect of $\mathrm{Ar}^{+}$ion beam irradiation on the physicochemical characteristics of carbon fibers. Carbon, 41, 592 (2003). http://dx.doi.org/10.1016/S0008-6223(02)00395-0.

[7] Park SJ, Park BJ. Electrochemically modified PAN carbon fibers and interfacial adhesion in epoxy-resin composites. J Mater Sci Lett, 18, 47 (1999). http://dx.doi.org/10.1023/A:1006673309571.

[8] Perepelkin KE. Oxidized (cyclized) polyacrylonitrile fibres: oxypan. A review. Fibre Chem, 35, 409 (2003). http://dx.doi. org/10.1023/B:FICH.0000020769.42823.31.

[9] Park SJ, Lee EJ, Kwon SH. Influence of surface treatment of polyimide film on adhesion enhancement between polyimide and metal films. Bull Korean Chem Soc, 28, 188 (2007). http://dx.doi org/10.5012/bkcs.2007.28.2.188.

[10] Park SJ, Park BJ, Ryu SK. Electrochemical treatment on activated carbon fibers for increasing the amount and rate of $\mathrm{Cr}(\mathrm{VI})$ adsorption. Carbon, 37, 1223 (1999). http://dx.doi.org/10.1016/S00086223(98)00318-2.

[11] Bajaj P, Sreekumar TV, Sen K. Thermal behaviour of acrylonitrile copolymers having methacrylic and itaconic acid comonomers. Polymer, 42, 1707 (2001). http://dx.doi.org/10.1016/S00323861(00)00583-8.

[12] Bansal RC, Donnet JB, Stoeckli F. Active Carbon, Marcel Dekker, New York, NY (1988).

[13] Grassie N, Hay JN. Thermal coloration and insolubilization in polyacrylonitrile. J Polym Sci, 56, 189 (1962). http://dx.doi org/10.1002/pol.1962.1205616316.

[14] Shin HK, Jeun JP, Kim HB, Kang PH. Isolation of cellulose fibers from kenaf using electron beam. Radiat Phys Chem, 81, 936 (2012). http://dx.doi.org/10.1016/j.radphyschem.2011.10.010.

[15] Park M, Shin HK, Kim BS, Pant B, Barakat NAM, Kim HY. Facile preparation of graphene induced from electron-beam irradiated graphite. Mater Lett, 105, 236 (2013). http://dx.doi.org/10.1016/j. matlet.2013.04.027.

[16] Shin HK, Park M, Kang PH, Choi HS, Park SJ. Preparation and characterization of polyacrylonitrile-based carbon fibers produced by electron beam irradiation pretreatment. J Ind Eng Chem, 20, 3789 (2014). http://dx.doi.org/10.1016/j.jiec.2013.12.080.

[17] Shin H, Jeun JP, Kang PH. The characterization of polyacrylonitrile fibers stabilized by electron beam irradiation. Fibers Polym, 13, 724 (2012). http://dx.doi.org/10.1007/s12221-012-0724-5.

[18] Choi Y, Park M, Kyoung Shin H, Liu Y, Choi JW, Nirmala R, Park SJ, Kim HY. Facile stabilization process of polyacrylonitrile-based electrospun nanofibers by spraying $1 \%$ hydrogen peroxide and electron beam irradiation. Mater Lett, 123, 59 (2014). http://dx.doi. org/10.1016/j.matlet.2014.03.020. 